\title{
Land surface temperature estimation using split window approach over US Nagar district of Uttarakhand state, India
}

DANIEL PRAKASH KUSHWAHA, VIJAY KUMAR SINGH AND TARATE SURYAKANT BAJIRAO

Received : 21.04.2017; Revised : 27.07.2017; Accepted : 11.08.2017

See end of the Paper for authors' affiliation

Correspondence to :

\section{DANIEL PRAKASH}

\section{KUSHWAHA}

Department of Soil and Water Conservation Engineering, College of Technology, G.B. Pant University of Agriculture and Technology, Pantnagar, U.S. NAGAR (UTTARAKHAND) INDIA

Email : danielprakash45499@ gmail. com
- ABSTRACT : To estimate land surface temperature (LST) has an important role for agriculture as well as global change of climate, growth of vegetation and glacier melting. It combines the results of all surface atmosphere interactions and energy fluxes between the surface and the atmosphere. Now-a-days, estimation of temperature of land surface is being calculated with the help of satellite images containing thermal infrared band. Though land surface temperature derived from satellite, could be a beneficial complement to conventional land surface temperature data sources. This research, proposed a methodology for determining land surface temperature through using a structured mathematical algorithm viz., split window (SW) algorithm. Split window algorithm has been used on LANDSAT 8 with operational land imager i.e. OLI sensor and thermal infrared sensor i.e. TIRS dataset of Udham Singh Nagar district. TIRS shows two thermal bands i.e. band 10 and band 11. SW approach requires brightness temperature value of both band 10 and band 11 as well as land surface emissivity which is calculated from OLI bands i.e. NIR and Red, for the estimation of land surface temperature. The spectral radiance was determined using thermal infrared bands i.e. band 10 and band 11. Emissivity was calculated by using normalized difference vegetation index i.e. NDVI threshold technique for which OLI bands 2, 3, 4 and 5 were utilized. SW approach uses brightness temperature of two bands of thermal infrared, mean and difference in land surface emissivity for estimating land surface temperature. In this paper, 6 Dec. 2015 date was selected as an example to show the approach of using SW technique to estimate the LST of Udham Singh Nagar district of Uttarakhand state in India.

- KEY WORDS : Split window approach, Fractional vegetation cover, Land surface emissivity, Land surface temperature

- HOW TO CITE THIS PAPER : Kushwaha, Daniel Prakash, Singh, Vijay Kumar and Bajirao, Tarate Suryakant (2017). Land surface temperature estimation using split window approach over US Nagar district of Uttarakhand state, India. Internat. J. Agric. Engg., 10(2) : 354-359, DOI: 10.15740/HAS/IJAE/10.2/354-359. 